\title{
Anesthetic Management of a Patient With Dandy-Walker Syndrome for Orthopedic Surgery
}

\author{
Mehmet Ilke Buget ${ }^{\mathrm{a}, \mathrm{b}}$, Ipek Saadet Edipoglu ${ }^{\mathrm{a}}$, Ezgi Cemaller ${ }^{\mathrm{a}}$, Semiha Eren ${ }^{\mathrm{a}}$, \\ Suleyman Kucukay ${ }^{\mathrm{a}}$
}

\begin{abstract}
Dandy-Walker syndrome (DWS) is a very rare congenital malformation. Its characteristic features are cystic dilatation of the fourth ventricle, enlarged posterior cranial fossa with upward displacement of the tentorium, and lateral sinuses with agenesis or hypoplasia of the cerebellar vermis. DWS is also associated with abnormalities in the skeletal, cardiac, and genitourinary systems. In this report, we aimed to present a case of a patient with DWS who was scheduled for achilloplasty surgery. We encountered a difficult airway during the anesthesia induction. As direct laryngoscopy was not possible, we preferred laryngeal mask for the airway maintenance.
\end{abstract}

Keywords: Dandy-Walker syndrome, Anesthesia; Difficult airway

\section{Introduction}

Dandy-Walker syndrome (DWS) is a very rare congenital malformation with an incidence ranging between $1 / 25,000$ and $1 / 35,000$ births. DWS is characterized by hypoplasia of the cerebellum and cystic dilatation of the fourth ventricle that results in enlargement of the posterior fossa. It clinically manifests an obstructive hydrocephalus with dilatation of the third and lateral ventricles frequently [1].

Anesthetic management of DWS patients can pose serious threats because of multisystemic association of craniofacial abnormalities, hydrocephalus, renal, and cardiac pathologies [2]. Difficulties in intubation are frequently encountered [3].

In this report, we aimed to present a case of a patient with DWS who was scheduled for achilloplasty surgery.

Manuscript accepted for publication July 29, 2015

aDepartment of Anesthesiology, Istanbul University, Istanbul Medical Faculty, Istanbul, Turkey

${ }^{b}$ Corresponding Author: Mehmet I. Buget, Department of Anesthesiology, Istanbul University, Istanbul Medical Faculty, 34093, Fatih, Istanbul, Turkey. Email: mbuget@yahoo.com

doi: http://dx.doi.org/10.14740/jmc2255e

\section{Case Report}

We obtained the written informed consent of the patient's parents. We admitted a 2.5-year-old boy to hospital with the diagnosis of walking disorder for achilloplasty surgery and the surgery was scheduled for tendon lengthening.

The patient was treated in neonatal intensive care unit for 20 days with apnea periods in his anamnesis. On physical examination, his length was $90 \mathrm{~cm}$ (50th percentile), he weighed $14 \mathrm{~kg}$ (50th percentile), and he had a head circumference of 53 $\mathrm{cm}$ (97th percentile). We determined macrocephaly, micrognathy, macroglossy, bilateral pes equinovarus and kyphoscoliosis. There were no abnormalities in cardiovascular and urogenital systems.

We used standard ASA monitoring which includes fivelead electrocardiogram, $\mathrm{SpO}_{2}$, non-invasive blood pressure, and end-tidal carbon dioxide. Anesthesia induction was done with inhalation technique by face mask and spontaneous ventilation was maintained. Inhalational induction was performed with $8 \%$ sevoflurane in $100 \%$ oxygen. A Guedel airway was required to keep the airway patent during induction. Bag valve mask ventilation was maintained successfully. A 22-G intravenous cannula was inserted and secured in the patient's vein. Also, $0.5 \mu \mathrm{g} / \mathrm{kg}$ fentanyl and $0.6 \mathrm{mg} / \mathrm{kg}$ rocuronium were given to the patient. When we attained sufficient depth of anesthesia, we performed the conventional laryngoscopy with Miller blade size 1 twice and we recorded a McCormack and Lehane grade III-IV view. Blind intubation was not attempted. Size 2 laryngeal mask airway (LMA) was inserted successfully. Adequate ventilation was confirmed by capnography and bilateral normal breathing sounds. We elevated the head of the patient $10^{\circ}$. Mechanical ventilation was adjusted to keep end tidal $\mathrm{CO}_{2}$ levels at $35 \mathrm{~mm} \mathrm{Hg}$. Surgery lasted approximately $1 \mathrm{~h}$ and anesthesia was maintained with sevoflurane. At the end of the surgery, the LMA was removed from the patient without any complication. Postoperatively, at the time of early recovery, the modified Aldrete score was 9. We kept the patient in the recovery room for $45 \mathrm{~min}$, and he was moved to his room only after the modified Aldrete score reached to 10.

\section{Discussion}

There are many reports about DWS in other medical sciences 
but publications associated with anesthesia are limited. The reports on DWS commonly include syndrome craniofacial abnormalities such as cleft palate, micrognathia and hypertelorism, and cardiac, renal and skeletal malformations such as limb and vertebral abnormalities [4]. Cerebral anomalies with agenesis of the corpus callosum occurred and the patients have poor intellectual development. Also pontine lesions that involve the apneustic interference with medullary control of respiration center may produce uninterrupted respiratory spasm or apneustic breathing $[3,4]$. The uninterrupted respiratory spasm or apneustic breathing leads to respiratory failure [4]. The prognosis of the syndrome differs and almost $40 \%$ of the children suffer from severe mental retardation. Forty percent of DWS children are mentally normal and $20 \%$ are borderline patients [5].

DWS has been attributed to various types of chromosomal abnormalities. It creates difficulties in airway management. Airway management of a patient with DWS requires planning and use of alternative techniques in order to secure the airway. In securing airway, patient bag valve mask ventilation was maintained successfully and thus conventional laryngoscopy was attempted. We could not visualize the vocal cords. To avoid airway irritation, we decided to use alternative techniques such as LMA. We could utilize LMA as a conduit for the fiberoptic intubation but we did not prefer to do so because the duration of the surgery was short and in order to avoid raising intracranial pressure. We followed DAS guidelines for pediatric airway and used LMA after failed direct laryngoscopy attempts [6]. Selim et al used LMA for airway management for a 5-month-old DWS child successfully [7]. Other alternatives for difficult intubation were fiber-optic intubation or blind oral-nasal intubation [8]. Sari et al used caudal blockade for neonate successfully and it may be another alternative for the appropriate surgery [9]. But increased intracranial pressure is seen nearly in all DWS cases (i.e. $90 \%$ ) and there is no consensus concerning applying neuroaxial anesthesia to patients with hydrocephalus [10].

For DWS patients, another important issue is maintaining stable intracranial pressure during the anesthesia period. We kept the patient in normothermic and normoglycemic condition during the operation period. Proper positioning of the patient can diminish ICP. A study on craniotomy showed a decreased ICP, without a change in CPP in cerebral aneurysm patients, when a $10^{\circ}$ head-up position was used $[11,12]$. We also preferred a $10^{\circ}$ head elevation in our case. Hypocapnic cerebral vasoconstriction is effective for manipulating cerebral blood flow (CBF). Hyperventilation can be employed to sustain brain relaxation. But as the hyperventilation diminishes $\mathrm{CBF}$, prolonged usage can theoretically exacerbate cerebral ischemia. So it is reasonable to keep the $\mathrm{PaCO}_{2}$ levels between 30 and $35 \mathrm{~mm} \mathrm{Hg}$ during neurosurgical operations of short durations like the surgery duration in our case [13].

Most neurosurgical operations can be maintained with volatile agents. Also opioids should be used to diminish volatile anesthetic requirements. To maintain sufficient brain relaxation, usage of volatile anesthetic with less than 1 MAC is appropriate [13]. Sevoflurane seems to be one of the most appropriate inhaler agents for maintenance of neuro-anesthesia [14].

Systemic malformations were observed on $47-81 \%$ of
DWS patients. These malformations include urogenital, renal, cardiac, intestinal, and craniofacial defects $[5,14]$. Our patient did not have any renal or cardiac malformation and we did not encounter any problems during the operation.

In conclusion, in patients with DWS, difficult intubation can be expected. LMA is a suitable option in difficult airway management without raising the intracranial pressure for DWS children.

\section{Conflicts of Interest}

None declared.

\section{Funding}

None.

\section{References}

1. Brown JR. The Dandy-Walker Syndrome. In: Vinken PJ, Bruyn GW, Klawans HL, Eds. Handbook Of Clinical Neurology, Vol. 30. Amsterdam: Elsevier Science Publishers, 1977: 62346.

2. Celik F, Tufek A, Temel T, Akdemir S, Yildirim ZB, Kavak GO. Anesthesia management in a pediatric patient with Dandy-Walker syndrome. Journal of Clinical and Experimental Investigations. 2011;2(3):327-329.

3. Ewart MC, Oh TE. The Dandy-Walker syndrome. Relevance to anaesthesia and intensive care. Anaesthesia. 1990;45(8):646-648.

4. Krieger AJ, Detwiler J, Trooskin S. Respiration in an infant with the Dandy-Walker syndrome. Neurology. 1974;24(11):1064-1067.

5. Klein O, Pierre-Kahn A, Boddaert N, Parisot D, Brunelle F. Dandy-Walker malformation: prenatal diagnosis and prognosis. Childs Nerv Syst. 2003;19(7-8):484-489.

6. Henderson JJ, Popat MT, Latto IP, Pearce AC. Difficult Airway Society guidelines for management of the unanticipated difficult intubation. Anaesthesia. 2004;59(7):675694.

7. Selim M, Mowafi H, Al-Ghamdi A, Adu-Gyamfi Y. Intubation via LMA in pediatric patients with difficult airways. Can J Anaesth. 1999;46(9):891-893.

8. Demircioglu RI, Ozanbarci A, Karabayirli S, Usta B, Andiran F. Anesthesia for The Patient With Dandy Walker Syndrome. Anestezi Dergisi. 2012;20 (4): 245-248.

9. Sari S, Gulasti F, Erdem AO, Akcan AB, Gursoy F. Caudal Anesthesia in a Neonate with Dandy-Walker Syndrome. J Syndromes. 2015;2(1):2.

10. Almenrader N, Passariello M, Coccetti B, Pietropaoli P. Anesthesia for a child with deletion $3 \mathrm{q}$ syndrome. Paediatr Anaesth. 2008;18(8):789-790.

11. Dinsmore J. Anaesthesia for elective neurosurgery. Br J Anaesth. 2007;99(1):68-74.

12. Tankisi A, Rasmussen M, Juul N, Cold GE. The effects 
of 10 degrees reverse Trendelenburg position on subdural intracranial pressure and cerebral perfusion pressure in patients subjected to craniotomy for cerebral aneurysm. J Neurosurg Anesthesiol. 2006;18(1):11-17.

13. Kincaid MS, Lam AM. Anesthesia for Neurosurgery. In: Barash Paul G, Cullen Bruce F, Stoelting Robert K,
Cahalan Michael K, Stock M. Christine. Eds. Clinical Anesthesia. 6th Edition. Lippincott Williams \& Wilkins; 2009:1006-1031.

14. Coban D, Akin MA, Kurtoglu S, Oktem S, Yikilmaz A. Dandy-Walker malformation: a rare association with hypoparathyroidism. Pediatr Neurol. 2010;43(6):439-441. 